\title{
CONTRIBUTION TO THE CHEMISTRY OF DRYING OILS; WITH A METHOD FOR THE EXAMINATION OF LINSEED OIL.
}

\author{
By Otto Hehner and C. A. Mitchell, B.A.
}

(Read at the Meeting, November 2, 1898.)

Our present knowleage of the composition and constitution of the fluid fatty acids occurring in natural fluid glycerides dates back no further than the year 1888, when $\mathrm{K}$. Hazura, together with a number of collaborateurs, published a series of exceedingly important papers in the Monatshefte für Chemie. Up to that time the fluid portion of oils, drying and non-drying, was described as olein.

Hazura showed that when fluid fatty acids obtained from various oils were oxidized in alkaline solution with potassium permanganate, a number of different hydroxy-derivatives were produced. He isolated and described the characteristics of these compounds, and concluded from his investigations that the unsaturated fatty acids from fixed oils take up as many hydroxyl groups as there are free valencies, yielding saturated hydroxy-fatty acids containing the same number of carbon atoms as the original molecule. He also showed that the unsaturated fatty acids in question combined directly with bromine, as many bromine atoms being fixed as there are free valencies. He thus differentiated between acids of different degrees of nonsaturation, and supplied a scientific explanation of the Hübl iodine value.

We give in a tabular form a statement of his results :

TABLE I.

\begin{tabular}{|c|c|c|c|c|}
\hline Original Acid. & Bromo-compound. & M.P. & Oxidation Product. & M.P. \\
\hline $\begin{array}{l}\text { Oleic } \\
\qquad\left(\mathrm{C}_{18} \mathrm{H}_{34} \mathrm{O}_{2}\right)\end{array}$ & $\begin{array}{l}\text { Dibrom- } \\
\text { stearic acid }\end{array}$ & Liquid & $\begin{array}{l}\text { Dihydroxy- } \\
\text { stearic acid }\end{array}$ & $137^{\circ} \mathrm{C}$. \\
\hline $\begin{array}{l}\text { Linolic } \\
\qquad\left(\mathrm{C}_{18} \mathrm{H}_{32} \mathrm{O}_{2}\right)\end{array}$ & Tetrabrom- & $114-115^{\circ} \mathrm{C}$. & $\begin{array}{l}\text { Sativic acid } \\
\mathrm{C}_{18} \mathrm{H}_{32}(\mathrm{OH})_{4} \mathrm{O}_{2}\end{array}$ & $173^{\circ} \mathrm{C}$. \\
\hline $\begin{array}{l}\text { Linolenic } \\
\qquad\left(\mathrm{C}_{18} \mathrm{H}_{30} \mathrm{O}_{2}\right)\end{array}$ & $\begin{array}{l}\text { Hexabrom- } \\
\text { stearic acid }\end{array}$ & $177^{\circ} \mathrm{C}$. & $\begin{array}{l}\text { Linusic acid } \\
\qquad \mathrm{C}_{18} \mathrm{H}_{30}(\mathrm{OH})_{6} \mathrm{O}_{2}\end{array}$ & $203^{\circ} \mathrm{C}$. \\
\hline $\begin{array}{l}\text { Isolinolenic } \\
\qquad\left(\mathrm{C}_{18} \mathrm{H}_{30} \mathrm{O}_{2}\right)\end{array}$ & - & - & $\begin{array}{l}\text { Isolinusic } \\
\mathrm{C}_{18} \mathrm{H}_{30}(\mathrm{OH})_{6} \mathrm{O}_{2}\end{array}$ & $173-175^{\circ} \mathrm{C}$. \\
\hline
\end{tabular}


From the yields of the hydroxy-derivatives, which, as will be seen from the following tables, were very far from quantitative, Hazura and Grüssner made an approximate estimation of the composition of the unsaturated acids of a number of oils :

\begin{tabular}{|c|c|c|c|c|c|c|}
\hline & & & $\begin{array}{l}\text { CE II. } \\
\text { Gramme }\end{array}$ & iquid $\mathrm{F}$ & cids yiel & \\
\hline Dihydroxy-stearic acid & $\cdots$ & $\begin{array}{c}\text { Linseed. } \\
1.2\end{array}$ & $\begin{array}{c}\text { Hemp. } \\
4.0\end{array}$ & $\begin{array}{l}\text { Nut. } \\
2.5\end{array}$ & Poppy. & $\begin{array}{r}\text { Cotton } \\
23 \cdot 0\end{array}$ \\
\hline Sativic acid $\ldots$ & $\ldots$ & 6.5 & $24 \cdot 0$ & $25 \cdot 0$ & 18.5 & 31.5 \\
\hline Linusic + isolinusic acids & & $20 \cdot 3$ & $2 \cdot 5$ & $2 \cdot 0$ & $0 \cdot 3$ & - \\
\hline & & $28 \cdot 0$ & $30 \cdot 5$ & $29 \cdot 5$ & $27 \cdot 3$ & $54 \cdot 5$ \\
\hline
\end{tabular}

TABLE III.

Approximate Percentage Composition of Liquid Fatty Acids.

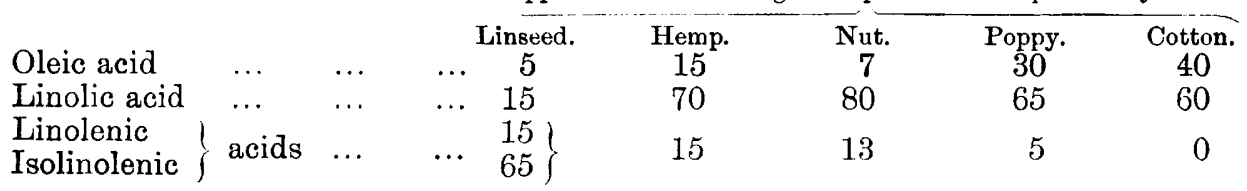

It is obvious from the numbers given in Table II. that there must have been a considerable destruction of the first products of oxidation, especially of those derived from the least saturated acids ; Hazura, in fact, obtained a number of further oxidationproducts, indicating the rupture of the molecule. Nevertheless, it may be interesting to compare Hazura's estimates and the iodine values deduced therefrom, with the actual iodine numbers recorded for the fatty acids from the several oils, bearing in mind that the latter are for the total free fatty acids, while Hazura's numbers are for the unsaturated acids only.

\begin{tabular}{clllllc}
\multicolumn{8}{c}{ TABLE IV. } \\
\multicolumn{1}{c}{ Linseed. } & Hemp. & Nut. & Poppy. & Cotton. \\
Iodine number calculated from & & & & & \\
$\quad$ Hazura's results $\ldots$ & $\ldots$ & 251 & 181.5 & 187 & 158 & 145 \\
Iodine value of total acids & $\ldots$ & $160-180$ & 141 & 145 & 139 & 113
\end{tabular}

The calculated iodine value of oleic acid is 90 ; of linolic acid, 181.4; and of linolenic and isolinolenic acid, 274·1.

With regard to isolinolenic acid, Hazura and Grüssner inferred its existence solely from the oxidation-products formed; they did not obtain a bromo-derivative, and hence did not isolate the acid.

After making allowance for the presence of saturated fatty acids, it will be seen that there is an approximate correspondence between the calculated and the actual figures in the case of all but the linseed oil, which is said to contain about 15 per cent. of solid acids.

We have repeated some of Hazura's work, and have prepared some, at least, of the derivatives discovered by him, paying particular attention to the brominederivatives. 
On adding a sufficiency of bromine to an ethereal or acetic acid solution of linseed fatty acids, kept at a temperature of about $5^{\circ}$ C., an abundant precipitate immediately forms. Part of this is exceedingly insoluble, while a part can be washed away with ether. The insoluble portion is the hexabrom-derivative of Hazura, although the composition of the substance does not exactly correspond with the formula, even after extraction for days with ether.

Thus, in four separate experiments we obtained compounds with the following percentages of bromine :

$\begin{array}{lc}\text { Found. } & \text { Theoretical. } \\ \text { 1. } 61 \cdot 38 & 63 \cdot 31 \\ \text { 2. } 61 \cdot 47 & \\ \text { 3. } 61 \cdot 80 & \\ \text { 4. } 61 \cdot 64 & \end{array}$

We found the melting-point from $180^{\circ}$ to $181^{\circ} \mathrm{C}$., while Hazura gives $177^{\circ} \mathrm{C}$. We determined the percentage of bromine-derivative yielded by a considerable number of samples of linseed oil fatty acids, and found them to vary from 20 to 26 per cent. Hazura obtained from 100 parts of the fluid linseed oil acids 40 of hexabromide, having a melting-point of $177^{\circ} \mathrm{C}$. We believe that his precipitates must have included a considerable proportion of tetrabromide, seeing that it is difficult to entirely wash the latter out, as the above analyses of the persistently washed products show.

After the hexabromide has been filtered off, precipitates are obtainable which contain upwards of 50 per cent. of bromine, the tetrabromide formula requiring 53.32 per cent. of bromine. The part remaining in solution, when recovered by the evaporation of the solvent, consists of a semi-solid mass, evidently a mixture of dibromide and tetrabromide. This we found to contain 45 per cent. of bromine, the pure dibromide requiring 36.18 per cent. The tetrabromide of Hazura can be much more readily obtained from maize oil fatty acids than from linseed. But here, again, the actual percentage of bromine, even after numerous crystallizations from alcohol, falls somewhat short of the theoretical amount. Our product contained 51.97 per cent. of bromine, against a theoretical 53.32 per cent. The melting-point was $113.4^{\circ} \mathrm{C}$. (corr.), against Hazura's $114^{\circ}$ to $115^{\circ} \mathrm{C}$.

The dibromide we have not been able to obtain in a pure condition.

On boiling the hexa- and tetra-bromine compounds with alcoholic potassium hydroxide the bromine is entirely eliminated. Theory requires for complete elimination of the bromine from the hexa-compound 51.8 per cent. of potassium hydroxide. In four separate determinations $51 \cdot 33,51 \cdot 61,51 \cdot 50$, and $51 \cdot 5$ per cent. of potassium hydroxide were consumed. On liberating the free acids from the resulting alkali salts no crystallizable substances could be obtained, the products being viscid yellow oils, which did not dry after being exposed to the air for a week, and which were, therefore, neither the hydroxyacids, which result from oxidation by permanganate, nor the less saturated products which would have resulted from an elimination of $6 \mathrm{HBr}$ from the molecule. At the same time, the oil absorbed iodine from Hübl's solution to the extent of 61 to 63 per cent. After the titration of the excess of iodine added, the solutions rapidly became blue again from the further liberation of iodine. On re-bromination hydrobromic acid was evolved, and the original hexabromide was not reproduced. In this particular it behaved like the acids from boiled linseed oil. 
The bromine can likewise be completely removed from the dibromides and tetrabromides by boiling with alcoholic potassium hydroxide, and the acids thus obtained are also oily fluids with low iodine absorption.

Hazura, by reduction of the hexa-bromide with zinc and hydrochloric acid, prepared linolenic acid, which, however, owing to its oxidizable nature, could not be obtained pure and with the theoretical iodine value. He found 245 , as compared with the theoretical $274 \cdot 1$. We have also made efforts in this direction, taking every precaution to keep away oxygen, yet were not more successful, since the iodine absorption of our linolenic acid only reached $241 \cdot 8$. The acid obtained was a nearly colourless oil of a specific gravity 0.9228 at $15.5^{\circ} \mathrm{C}$. (compared with water at the same temperature) which absorbed oxygen from the air with great rapidity and quickly became dark brown. On dissolving this linolenic acid in acetic acid and adding bromine, the hexabromide was produced, but not quantitatively, only 46 to 50 per cent. of the yield being obtainable; dense fumes of hydrobromic acid were given off. With the advance of oxidation in a linseed oil the yield of hexabromide decreases with the decrease in the iodine value. A linseed oil with an original iodine value of $160 \cdot 7$, with a yield of hexabromide of 22.5 per cent. (probably not quite pure hexacompound) on the fatty acids, was heated on the water-bath for a day and air blown through at intervals. The iodine value of the fatty acids was $147 \cdot 3$, and the yield of insoluble bromo-compound obtained under precisely the same conditions as before was 16.7 and 15.9 per cent. respectively in two determinations. A sample of boiled linseed oil, with an iodine value of $115 \%$, gave absolutely no precipitate on treatment with bromine, but hydrobromic acid was evolved. It appears probable to us that the amount of hydrobromic acid produced will be found to be a measure of such oxidation as occurs during the "boiling" of linseed and other oils. It will be remembered that McIlhiney (ANALYST, xix., 141) has already made experiments, from which he deduces a method for the determination of resin-acids in linseed oil, based upon the elimination of hydrobromic acid on bromination.

We have also submitted the unsaturated fatty acids obtained from maize oil to oxidation with alkaline permanganate, and are in a position to entirely confirm Hazura's statements as to the composition and properties of sativic acid, except that the melting-point of our purest substance was $174^{\circ}$, instead of $173^{\circ}$ as found by him.

Acting upon the fatty acids liberated from other oils with bromine, we found that almond oil, with an iodine value of 95.68 , gave no solid product of any kind. Mixtures of almond and linseed oil acids yielded amounts of insoluble bromide corresponding very approximately to the percentage of the linseed oil acids present, provided the operations were always carried out under precisely the same conditions as to amount of acids taken, temperature, solvent used, and washing. Quantities of from 0.2 to 0.3 grammes of the fatty acids were dissolved in 10 c.c. of acetic acid and the solution cooled to $5^{\circ} \mathrm{C}$. in a corked flask. Bromine was then added drop by drop until a permanent bromine colour was observed. After standing for three hours the liquid was filtered through a Soxhlet tube containing asbestos, and washed with chilled acetic acid, alcohol, and ether, in successive portions of 5 c.c. each. The residue, which was white, was dried in the water-oven to constant weight. Attempts to use 
larger quantities of fatty acid were unsuccessful, owing to the difficulty of filtration and washing until colourless in a Soxhlet tube.

TABLE V.

\begin{tabular}{|c|c|c|c|}
\hline Acids used. & $\begin{array}{l}\text { Linseed Oil, } \\
\text { Per Cent. }\end{array}$ & $\begin{array}{c}\text { Insoluble Bromide, } \\
\text { Per Cent. }\end{array}$ & $\begin{array}{l}\text { Linseed Oil Acid eal- } \\
\text { culated from Bromide. }\end{array}$ \\
\hline Linseed oil ... & 100 & 21 & \\
\hline Almond oil ... & $\ldots$ & 0 & 0 \\
\hline Linseed + almond & $7 \cdot 9$ & 162 & $7 \cdot 7$ \\
\hline ," & $8 \cdot 7$ & 1.97 & $9 \cdot 3$ \\
\hline, & $20 \cdot 2$ & $4 \cdot 24$ & $20 \cdot 1$ \\
\hline$"$ & $37 \cdot 5$ & $7 \cdot 53$ & $35 \cdot 3$ \\
\hline Poppy oil $\quad \ldots$ & $\ldots$ & 0 & 0 \\
\hline Poppy + linseed & $18 \cdot 3$ & $3 \cdot 35$ & 16 \\
\hline ", $\quad$, & $37 \cdot 3$ & $8 \cdot 17$ & $38 \cdot 9$ \\
\hline Cotton-seed oil & $\ldots$ & 0 & 0 \\
\hline Cotton-seed + linseed & $43 \cdot 3$ & $8 \cdot 43$ & $40 \cdot 1$ \\
\hline , & $60 \cdot 1$ & $11 \cdot 6$ & $55 \cdot 2$ \\
\hline
\end{tabular}

It need hardly be said that poppy-seed and cotton-seed oil acids also furnish the tetrabromide, which, however, comes down more slowly than the hexabromide, and is more or less completely removed by washing the deposit. The deposit from poppyseed oil acids melted at $112^{\circ} \mathrm{C}$, and that from cotton-seed oil acids at $113^{\circ} \mathrm{C}$.

Although the results stated in the preceding table are fairly satisfactory, yet the method is so empirical as not to commend itself. Moreover, when larger quantities of acids are operated upon, tetrabromide is apt to come down simultaneously with the hexa-compound, and to wash this free from the former considerable quantities of solvent are necessary, in which the hexabromide is not completely insoluble.

A more reliable method is to obtain the mixture of solid compounds, washing this but slightly in order to remove readily soluble dibromide, and then to determine the percentage of bromine in the dried and weighed precipitate. From the amount of bromine found it is easy to calculate the relative proportion of the hexabromide in the mixture by means of the formula

$$
\frac{63 \cdot 3 x}{100} \times \frac{(100-x) 53 \cdot 3}{100}=m
$$

or $10 x=100(m-53 \cdot 3)$ or $x=10(m-53 \cdot 3)$, in which $m$ equals the percentage of bromine found, $x$ the required percentage of hexabromide, and 63.3 and 53.3 the respective percentage of bromine in the pure hexa- and tetra-compounds.

To illustrate this mode of working an outline of an experiment on linseed oil acids may be described. About 2 grammes of linseed oil acids (which by the method used in the experiments given in Table V. yielded from 20 to 23 per cent. of insoluble bromides) were brominated, but the deposit was washed with a far larger amount of acetic acid and ether than previously mentioned. By this washing the amount of deposit was reduced to 13 per cent., which melted at $179^{\circ}$ C., and was therefore practically pure hexabromide. The filtrate and washings were allowed to concentrate spontaneously, whereby a further crystalline deposit amounting to $8 \cdot 16$ per cent. was 
obtained. This deposit contained 58.8 per cent. of bromine, which, calculated by the formula given above, corresponds to 4.48 per cent. of hexabromide. Hence, the total percentage of hexabromide equalled $17 \cdot 48$. The filtrate from the second precipitate did not yield any further solid deposit, but only a heavy yellow oil.

This mode of operating may afford a solution of the problem of determining the relative percentages of oleic, linolic and linolenic acids in a mixture of fluid fatty acids, provided the saturated fatty acids are first separated. Further experiments on this important point will be carried out.

The idea naturally suggests itself to obviate the separation of the acids from oils and to operate upon the glycerides instead. When an oil, the fatty acids of which give insoluble bromine-compounds, is dissolved in ether or other suitable solvent, and bromine is added, there is an immediate precipitate produced, which is much more insoluble than the acid hexabromide, and consequently can be washed readily and efficiently. The precipitate can be collected either in a Soxhlet tube, if the quantity taken is small, or on a counterpoised filter, but we recommend the method of working which we employed for the estimation of stearic acid in mixtures of fatty acids (see Analyst, vol. xxi., p. 322); but instead of filtering through cotton we find the best filtering material to be thin flexible chamois-leather tied over the end of the small thistle-funnel, from which any adhering precipitate can afterwards readily be removed by washing.

From 1 to 2 grammes of the glycerides are dissolved in 40 c.c. of ether, to which a few c.c. of glacial acetic acid are added, the precipitate forming being more granular from such a mixture than when ether alone is employed. The solution is cooled in an ice-chest and bromine added, the flask being preferably left all night in the ice. This, however, is not essential for ordinary working. The liquid is filtered off by the suction-funnel attached to a pump, the flask washed out with four successive portions of 10 c.c. of ether at $0^{\circ} \mathrm{C}$, and the resiclue dried in the flask to constant weight. But even when ether at ordinary temperature is used, no considerable error is introduced.

Various samples of pure linseed oil were examined by this method, with the following results :

Table VI.

$\begin{array}{crcc}\text { Sample. } & \text { Oil taken. } & \text { Weight of Precipitate. } & \text { Percentage of Depwsit. } \\ \text { A } & 1 \cdot 3226 & 0 \cdot 3156 & 23 \cdot 86 \\ \text { A } & 3 \cdot 1005 & 0 \cdot 7573 & 24 \cdot 42 \\ \text { B } & 0 \cdot 6792 & 0 \cdot 1765 & 25 \cdot 8 \\ \text { C } & 1 \cdot 0000 & 0 \cdot 2480 & 24 \cdot 8 \\ \text { C } & 1 \cdot 0000 & 0.2500 & 25 \cdot 0\end{array}$

A sample of walnut oil gave, in two determinations, 1.9 and 1.42 per cent. of bromo-compound. Poppy oil (four specimens) gave no deposit, nor did brazil-nut oil, maize oil, cotton-seed oil, olive oil, Japanese wood oil, or almond oil. Mixtures of linseed oil and other oils gave percentages of bromine-compound in proportion to the percentage of linseed oil, as will be seen from the following table: 


\begin{tabular}{|c|c|c|c|}
\hline Oils Used. & $\begin{array}{l}\text { Linseed Oil, } \\
\text { Per Cent. }\end{array}$ & $\begin{array}{l}\text { Insoluble Bromide, } \\
\text { Per Cent. }\end{array}$ & $\begin{array}{l}\text { Linseed Oil calculated } \\
\text { from Bromide. }\end{array}$ \\
\hline Linseed $\mathrm{A}$ and walnut & .. 69 & $16 \cdot 6$ & 69 \\
\hline , & $38 \cdot 2$ & $9 \cdot 3$ & $38 \cdot 1$ \\
\hline Linseed $A$ and maize oil & 52 & $12 \cdot 4$ & $50 \cdot 8$ \\
\hline ", & $50 \cdot 5$ & $12 \cdot 2$ & $50 \cdot 0$ \\
\hline ", & $51 \cdot 7$ & $12 \cdot 6$ & $51 \cdot 6$ \\
\hline
\end{tabular}

It will be seen from the above figures that the determination of the amount of the precipitate can usefully serve for testing the purity of unoxidized linseed oil. More extended investigation as to the variation in the proportion of the precipitateyielding substance would, of course, be necessary, although as far as we have gone the variation appears to be small.

Considerable interest is attached to the nature and composition of the insoluble bromine-compound. From its origin it cannot be identical with the acid hexabromide; this is also shown by its melting-point, which is from $143.5^{\circ}$ to $144^{\circ} \mathrm{C}$, against hexabromide $\left(177^{\circ} \mathrm{C}\right.$, Hazura ; $180^{\circ}$ C. to $181^{\circ}$ C., Hehner and Mitchell). If it were hexabromo-linolenic glyceride, it would contain 62.28 per cent. of bromine. It cannot be linolic tetrabromo-glyceride with 52.23 per cent. bromine, since maize oil does not furnish any insoluble compound, while the free acids readily yield large amounts of the acid tetrabromo-derivative. We have made a considerable number of bromine determinations, which gave remarkably constant results. In various preparations we found $56 \cdot 38,55 \cdot 7,56 \cdot 38,56 \cdot 32,55 \cdot 55,56 \cdot 17$, and $56 \cdot 32$ per cent. bromine. This percentage is too low for the hexabromo-glyceride and too high for the tetrabromo-compound. Dr. Streatfield, of the Finsbury Technical College, was kind enough to make carbon and hydrogen determinations of a specimen of the material. Its ultimate composition was as follows:

$\begin{array}{lllllr}\text { Carbon } & \ldots & \ldots & \ldots & \ldots & 32 \cdot 97 \\ \text { Hydrogen } & \ldots & \ldots & \ldots & \ldots & 5 \cdot 42 \\ \text { Bromine } & \ldots & \ldots & \ldots & \ldots & 56 \cdot 18 \\ \text { Oxygen } & \ldots & \ldots & \ldots & \ldots & 4 \cdot 44 \\ \text { Ash } \ldots & \ldots & \ldots & \ldots & \ldots & 0.99 \\ & & & & & 100 \cdot 00\end{array}$

Calculated for the ash-free material, the composition is as follows :

$\begin{array}{lllllr}\text { Carbon } & \ldots & \ldots & \ldots & \ldots & 33 \cdot 29 \\ \text { Hydrogen } & \ldots & \ldots & \ldots & \ldots & 5 \cdot 48 \\ \text { Bromine } & \ldots & \ldots & \ldots & \ldots & 56 \cdot 74 \\ \text { Oxygen } & \ldots & \ldots & \ldots & \ldots & 4 \cdot 49 \\ & & & & & 100 \cdot 00\end{array}$

We are inclined to attribute to the bromo-compound the formula $\mathrm{C}_{57} \mathrm{H}_{9 j} \mathrm{O}_{6} \mathrm{Br}_{14}$, which would require:

$\begin{array}{lllllr}\text { Carbon } & \ldots & \ldots & \ldots & \ldots & 34 \cdot 27 \\ \text { Hydrogen } & \ldots & \ldots & \ldots & \ldots & 4 \cdot 81 \\ \text { Bromine } & \ldots & \ldots & \ldots & \ldots & 56 \cdot 11 \\ \text { Oxygen } & \ldots & \ldots & \ldots & \ldots & 4 \cdot 81 \\ & & & & & 100 \cdot 00\end{array}$


It must be remembered that the substance, on account of its insolubility, could not be purified by crystallization. In addition, the presence of mineral matter, probably derived from the oil itself, would tend to make deductions from the results still more uncertain. The percentage of bromine in the substance strongly points towards a mixed bromo-ester, and we suggest, very tentatively, the following formula :

$$
\mathrm{C}_{3} \mathrm{H}_{5}\left\{\begin{array}{l}
\mathrm{C}_{18} \mathrm{H}_{29} \mathrm{O}_{2} \mathrm{Br}_{6} \\
\mathrm{C}_{18} \mathrm{H}_{29} \mathrm{O}_{2} \mathrm{Br}_{6} \\
\mathrm{C}_{18} \mathrm{H}_{33} \mathrm{O}_{2} \mathrm{Br}_{2}
\end{array}\right.
$$

which, however, cannot be definitely accepted until a perfectly pure specimen has been examined. We are the more inclined towards a mixed glyceride formula, since the existence of such mixed esters has been fairly well proved in the case of butterfat, and also because it is impossible to separate, even by persistently carried out recrystallization, the stearin from palmitin contained in animal fats. When, on the other hand, the glycerides are broken up by saponification, the separation is readily effected, and from the fatty acids separated from linseed oil a nearly pure hexabromide is readily obtained.

We have also made experiments with other classes of oils. Thus the acids of rape oil, which contains rapic acid, $\mathrm{C}_{18} \mathrm{H}_{34} \mathrm{O}_{3}$ (which, unlike ricinoleic acid, does not appear to be a hydroxy-acid), yielded with bromine 3.6 per cent. of an insoluble bromo-acid containing 58.6 per cent. of bromine, and having a melting-point of $179^{\circ} \mathrm{C}$. It was, therefore, neither the hexa- nor the tetrabromo-compound of Hazura. Rape oil itself gave 0.9 per cent. of insoluble precipitate only; this was not further examined. The similar mustard-husk oil gave a fine granular precipitate amounting to 1.5 per cent.

Some of the marine animal oils approach linseed oil in many of their properties, especially in their iodine absorption. It is interesting to note that the (impure) linolenic acid which we prepared from linseed oil had a marked odour of fish oil, and that pure linseed oil, when heated in steam, often emits a similar fishy smell.

The free acids prepared from cod-liver oil gave on bromination a white precipitate, which, when dried in the water-oven, became dark brown. It amounted to 18 per cent., and contained 62.91 per cent. of bromine (theory requires for the hexacompound 63.31 per cent.). The air-dried substance had no definite melting-point, but decomposed below $200^{\circ} \mathrm{C}$. Attempts were made to determine its melting-point in a sealed tube, but these also yielded no results.

The cod-liver oil itself (the glyceride) yielded with bromine an immediate precipitate, consisting partly of a solid substance, and partly of a heavy oil, which was difficult to separate from the former. Eventually a perfectly white solid substance was prepared, which amounted to 42.9 per cent. and contained 56.32 per cent. of bromine. It had no sharp melting-point, decomposition taking place before fusion occurred. Cod oil behaved in an analogous manner, yielding 35.5 per cent. of insoluble compound, which was not further examined.

Shark oil, similarly, gave 22 per cent. of a bromine compound, and whale oil 25 per cent.

The investigations of Hazura, both as regards the hydroxy-derivatives and the 
bromine compounds of the unsaturated fatty acids, are of such great importance that it seems surprising so little has been done by other observers since the publication of his papers. We trust that our small contribution to the subject will cause others to pursue research in this direction. We have already indicated in several places starting-points for further work, and we are convinced that valuable additions to our scanty knowledge of the unsaturated fatty acids would result. If our supposition of the existence of a compound glyceride of the unsaturated fatty acids be confirmed, it would probably furnish an explanation of the different properties of oils possessing similar chemical constants. 